\title{
Uso do Peeling Químico no Tratamento da Acne Grau II: Revisão Sistemática
}

\author{
Larissa Duca Araújol, Josy Quélvia Alves Brito²
}

\begin{abstract}
Resumo: A pele humana necessita de muitos cuidados, pois é o órgão que nos separa do meio externo. A Acne, doença de pele multifatorial, favorecida pelo crescimento da bactéria $P$. acnes dentro dos comedões produzidos pelo fechamento das glândulas sebáceas, causando desconforto social a quem é acometido pela doença. Esta doença acomete principalmente a adolescentes, ainda mais nos meninos que nas meninas, por conta do pico de testosterona durante a puberdade. Apresenta formação de comedões, pápulas e cistos, cuja evolução se comina no processo inflamatório de maior intensidade, o que causa abcessos e regiões de pústulas. Entretanto, há diversos produtos que podem ser utilizados para diversos tratamentos farmacológicos e estéticos que auxiliam na melhor aparência da pele acometida, um deles é o peeling químico, esta técnica utiliza a descamação da pele por meio de ácidos deixando a pele mais uniforme e mais lisa. Desta maneira, este artigo vem com o intuito de averiguar os efeitos do peeling químico no tratamento do acne. Para a realização da pesquisa, foi realizada uma investigação com abordagens qualitativa com ênfase na revisão de literatura integrativa, no qual, os dados retirados de literatura. Percebe-se que a acne do tipo II pode ser tratada com a utilização de peeling químico para maior descamação e uniformidade da pele. Pode-se concluir que os peelings químicos, em diversos trabalhos apresentam resultados bons para diversos distúrbios de pele destacando a acne, podendo ser solução de diversos materiais que agem nas células criando um ambiente de esfoliação.
\end{abstract}

Palavras de indexação: Acne vulgar grau II; Peelings químico; Pele.

\section{Use of Chemical Peels in the Treatment of Acne Grade II: Systematic Review}

\begin{abstract}
The human skin needs a lot of care, because it is the organ that separates us from the external environment. Acne, a multifactorial, hormonal-genetic, favored by the growth of the P. acnes bacterium within the comedones produced by the sebaceous gland closure, causing social discomfort to those who are affected by the disease. This disease affects mainly adolescents, even more boys than girls, because of the peak of testosterone during puberty. It presents formation of comedones, papules and cysts, in an operation that is not an inflammatory process of greater intensity, that causes abysses and regions of pustules. However, there are several products that can be used for various pharmacological and aesthetic treatments, which can be improved on your skin, are used for chemical treatment, are used to describe the skin through acids, leaving a smoother and smoother skin. In this way, this article with the intention of ascertaining the effects of non-acne treatment chemical treatment. To conduct the research, a qualitative research was carried out with revision in an integrated literature review, in which, the data taken from the literature. Realize that a type II acne can be treated with a chemical peel for greater peeling and evenness of the skin. It can be concluded that the chemical peels in several works result results for several disorders of skin highlighting an acne, being able to be solution of diverse materials that act in the cells creating an environment of exfoliation.
\end{abstract}

Keywords: Acne grade II; Chemical peeling; Skin.

\footnotetext{
${ }^{1}$ Faculdade independente do Nordeste Campus Vitória da Conquista - Curso de tecnólogo em Estética e Cosmética. Contato: lary_araujo123@hotmail.com;

${ }^{2}$ Graduação em Fisioterapia pela Faculdade de Tecnologia e Ciência. Professora na Faculdade Independente do Nordeste, fisioterapia dermatofuncional - Espaço Pilates. Preceptora de estágio - Instiituição/Faculdade Independente do Nordeste. Contato: josyalves@hotmail.com.
} 


\section{Introdução}

A pele pode ser entrendida como uma estrutura que separa o meio interno do externo, protegendo assim, o organismo das influências externas. Para Junqueira e Carneira a pele pode ser divida em três estruturas bem distintas, sendo elas: o manto lipídico, a camada córnea, e acamada espinhosa.

Acne é uma afecção que acomete $80 \%$ dos adolescentes, atingindo a parte pilossebáceas de algumas áreas do corpo (MANFRINATO,2009). As lesões de acne podem provocar alterações estéticas em decorrência da apresentação inicialmente de comedões ou "cravos" e, em um estágio mais avançado pápulas, pústulas, nódulos e cicatrizes escavadas, deprimidas e hipertróficas na pele (LIMA, 2006).

É possível observar que vários fatores interferem na fisiopatologia da doença, dentre elas estão os aspectos genético, hormonal, hiperprodução sebácea, hiperqueratinização folicular e aumento da colonização da bactéria Propionibacterium acnes (P. acnes) no ducto glandular (COSTA, 2007).

Acne é classificada de acordo ao grau de acometimento, podendo ser tópica, sistêmica, hormonal e cirúrgico (BONET, 2002). As técnicas para tratamento são diversas e incluem a utilização de recursos como: limpeza de pele, cosméticos e fármacos com antissépticos e antiinflamatórios,além da utilização de procedimentos estéticos para melhorar a aparência ou até mesmo reduzir as expressões das lesões acnêicas (GUERRA, 2013 ).

O peeling químico vem utilizando cada vez mais na estética onde o resultado tem sido visível no tratamento de rugas, melanoses, melasma, hiperpigmentação pós-inflamatória, cicatrizes atróficas e acne (ROTTA, 2008; GUERRA, 2013). Este tratamento consiste na aplicação de um ou mais agentes esfoliantes na pele, que vai provocar uma regeneração dos tecidos e a destruição das camadas da epiderme/derme. (BORGES, 2006).

Os indivíduos que possuem acne, principalmente os adolescentes, convivem muitas vezes com a inibição social, pois a lesões e cicatrizes são aspectos que refletem na autoimagem e consequentemente na autoestima, estimulando dessa maneira a busca por tratamento, incluindo os estéticos (THIBOUTOT, 1997).

Este artigo tem o intuito de responder a seguinte problemática: Quais os efeitos do 
peeling químico no tratamento do acne? Para tal foco é apresentado como objetivo geral averiguar os efeitos do peeling químico no tratamento do acne. Para isso foram elencados os seguintes objetivos específicos compreender as diferenças existentes entre os produtos cosméticos para peeling químico disponível no mercado; avaliar o produto identificando os ativos dos cosméticos profissionais utilizados nos protocolos de tratamento para esfoliação química; entender o processo da formação de acne nos pacientes para gerir uma melhor escolha de intervenção.

\section{Metodologia}

Quanto ao objetivo do trabalho, podemos destacar que este trabalho pode ser cclassificado como explorativo, pois, segundo Gil (2008) com esta pesquisa tenta-se proporcionar maior conhecimento sobre o peeling químico. Para isto, foram abordados aqui a caracterização da pesquisa de revisão sistemática.

Segundo Moulin, Oliveira e Rosa (2012) a classe de revisão de literatura é uma fase de grande importância para o estudo, nela é possível fundamentar melhor de forma teórica um dado ou caso que se queira contruir desenvolvendo assim a pesquisa, ela é baseada nos diversos levantamentos e análises publicadas sobre o tema, contextualizando-o.

Para a realização da pesquisa, foi realizada uma investigação em diversas fontes de informações com ênfase na revisão de literatura integrativa, no qual, os dados retirados da literatura foram as bases da discussão para nosso trabalho (VIANELLO, 2013).

A abordagem usada parte desta pesquisa, identificando o tipo acne e tratamentos à doença e o porquê de serem usados amplamente na cosmetologia.

A pesquisa foi realizada em sites de busca por artigos acadêmicos relacionados aos temas da pesquisa, como Google Scholar; Scielo, Lilacs e outros sites sobre o assunto de estética e saúde, bem como organizações com foco nas linhas da estética e áreas afins, podendo ser um estudo de caso, uma revisão de literatura ou uma pesquisa. A pesquisa foi realizada durante os ano de 2017 no intuíto de obter base para compreender melhor o tema.

As análises de dados para uma revisão bibliográfica se apresentam com fundamental importância em qualquer tipo pesquisa, pois assim, o observador pode analisar sua pesquisa de 
forma que o objeto da pesquisa seja melhor separado e investigado, pa ra este trabalho foi feito uma varredura de trabalhos já escritos sobre os assuntos tratados.

\section{Resultados e Discussão}

A partir da análise dos bibliográfias utilizadas, obtive-se resultados obtidos que possibilitam o levantar propostas de intervenção da técnica de Peelings para acne de segundo grau, destacando a importância do método para tratamento sobre os comedões que acometem os pacientes com tal infecção, o que acarreta no maior conhecimento téorico.

Sendo assim, a partir do método analisado podemos perceber que ele pode ser utilizado no tratramento de acne de segundo grau, principalmente como forma de limpeza para à pele do paciente evitando por algum tempo a reinfecção.

O banco de dados utilizado, iniciou-se com a leitura de bibliográfias ligados ao tema, posteriormente estes textos entraram em triagem para a escolha dos trabalhos que mais condiziam ao tema, restando 28 publicações com 13 anos de emissão, como destacado na tabela 1.

Tabela 1: Distribuição dos artigos que avaliaram o uso de peeling na acne de segundo grau.

\begin{tabular}{|c|c|c|c|c|c|}
\hline AUTOR & TEMA & OBJETIVO & MÉTODOS & RESULTADOS & ANO \\
\hline $\begin{array}{l}\text { MINISTÉRIO } \\
\text { DA SAÚDE }\end{array}$ & $\begin{array}{l}\text { Pesquisa sobre o } \\
\text { processo de } \\
\text { individualização } \\
\text { entre os jovens } \\
\text { no Brasil }\end{array}$ & \begin{tabular}{|lr} 
Desenvolver & \\
maneiras & de \\
multiplicar & os \\
olhares sobre & $\mathrm{a}$ \\
juventude & \\
brasileira &
\end{tabular} & $\begin{array}{l}\text { Pesquisa } \\
\text { qualiquantitativ } \\
\text { a entre os } \\
\text { jovens das } \\
\text { capitais } \\
\text { brasileiras }\end{array}$ & 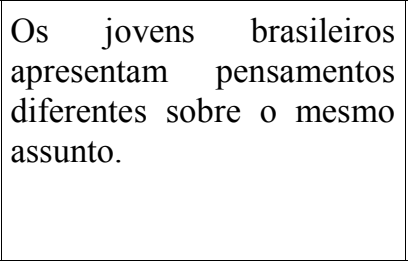 & 2008 \\
\hline $\begin{array}{l}\text { GONÇALVES; } \\
\text { RABEH; } \\
\text { TERÇARIOL }\end{array}$ & $\begin{array}{l}\text { Contribuição da } \\
\text { educação a } \\
\text { distância para o } \\
\text { conhecimento } \\
\text { dos docentes de } \\
\text { enfermagem }\end{array}$ & $\begin{array}{l}\text { Identificar a } \\
\text { contribuição de um } \\
\text { curso de atualização } \\
\text { sobre a avaliação de } \\
\text { feridas crônica }\end{array}$ & $\begin{array}{l}\text { Estudo } \\
\text { prospectivo } \\
\text { antes e depois } \\
\text { da aula sobre o } \\
\text { assunto; revisão } \\
\text { de literatura }\end{array}$ & $\begin{array}{l}\text { Maior acerto após o teste } \\
\text { saindo de } 55,5 \% \text { para } \\
73,4 \% \text { e efeito negativo } \\
\text { entre o tempo de aula e os } \\
\text { acertos do teste }\end{array}$ & 2015 \\
\hline $\begin{array}{l}\text { ARAÚJO; } \\
\text { DELGADO; } \\
\text { MARÇAL }\end{array}$ & $\begin{array}{l}\text { ACNE } \\
\text { DIFERENTES } \\
\text { TIPOLOGIAS } \\
\text { E FORMAS DE } \\
\text { TRATAMENT } \\
\text { O }\end{array}$ & $\begin{array}{l}\text { Pesquisar sobre a } \\
\text { acne, destacando a } \\
\text { sua tipologia e as } \\
\text { suas diferentes for } \\
\text { mas de tratamento } \\
\text { clínico. }\end{array}$ & $\begin{array}{l}\text { Revisão } \\
\text { bibliográfica }\end{array}$ & $\begin{array}{l}\text { Há possibilidades } \\
\text { terapêuticas para o } \\
\text { tratamento da acne, as } \\
\text { quais são dependentes } \\
\text { sobre tudo da tipologia da } \\
\text { afecção e do seu grau de } \\
\text { acometimento. }\end{array}$ & 2011 \\
\hline
\end{tabular}




\begin{tabular}{|c|c|c|c|c|c|}
\hline GATHAS et al & $\begin{array}{ll}\text { Queimaduras } & \\
\text { diante } & \text { os } \\
\text { diversos } & \\
\text { enfoques } & \text { do } \\
\text { cuidar } & \end{array}$ & $\begin{array}{l}\text { Produzir } \\
\text { conhecimentos } \\
\text { técnicos-científicos } \\
\text { a respeito dos } \\
\text { primeiros } \\
\text { atendimentos aos } \\
\text { pacientes queimados }\end{array}$ & $\begin{array}{l}\text { Revisão } \\
\text { literatura }\end{array}$ & $\begin{array}{l}\text { A assistência é complexa e } \\
\text { necessita de grande } \\
\text { conhecimento }\end{array}$ & 2011 \\
\hline MANFRINATO & $\begin{array}{lr}\text { Uso } & \text { da } \\
\text { Acupuntura } & \\
\text { estética } & \text { no } \\
\text { tratamento } & \text { da } \\
\text { acne } & \end{array}$ & $\mid \begin{array}{lr}\text { Compreender } \\
\text { melhor } & \text { a } \\
\text { da } & \text { acumplização } \\
\text { como } & \text { tratamento } \\
\text { alternativo para acne }\end{array}$ & Estudo de caso & $\begin{array}{l}\text { A acumpultura pode ser } \\
\text { usada como tratamento } \\
\text { alternativo para acne em } \\
\text { adolescentes a depender do } \\
\text { grau da acne }\end{array}$ & 2009 \\
\hline GUISTI et al & $\begin{array}{l}\text { Homeopatia } \\
\text { usada contra } \\
\text { acne }\end{array}$ & $\begin{array}{lr}\text { Descrever } & \text { muitos } \\
\text { pontos importantes } \\
\text { sobre a fisiologia, } \\
\text { quadro } & \text { clínico, } \\
\text { diagnóstico } & \mathrm{e} \\
\text { tratamento } & \end{array}$ & $\begin{array}{l}\text { Revisão de } \\
\text { literatura }\end{array}$ & $\begin{array}{l}\text { A homeopatia pode ser } \\
\text { usada como opção de } \\
\text { tratamento para acne, } \\
\text { entretanto alguns autores } \\
\text { mostram que a técnica } \\
\text { acabaria não sendo } \\
\text { diretamente ligada à acne }\end{array}$ & 2015 \\
\hline $\begin{array}{l}\text { ZAENGLEIN, } \\
\text { GRABER e } \\
\text { THIBOUTOT }\end{array}$ & $\begin{array}{l}\text { Dados } \\
\text { referentes à acne } \\
\text { vulgaris e as } \\
\text { lesões eruptivas }\end{array}$ & $\begin{array}{lrr}\text { Informar } & \text { os } \\
\text { diferentes } & \text { tipos } & \text { de } \\
\text { acne } & \text { e } \\
\text { características sobre } \\
\text { a epidemiologia }\end{array}$ & $\begin{array}{l}\text { Revisão de } \\
\text { literatura }\end{array}$ & $\begin{array}{l}\text { A maioria dos casos de acne } \\
\text { apresenta-se com um } \\
\text { arranjo pleomórfico de } \\
\text { lesões. }\end{array}$ & 2008 \\
\hline DIAS & $\begin{array}{l}\text { Contextualizaçã } \\
\text { o da utilização } \\
\text { dos fármacos de } \\
\text { peróxidos de } \\
\text { benzoíla r no } \\
\text { tratamento de } \\
\text { acne }\end{array}$ & $\begin{array}{l}\text { identificar e dosar de } \\
\text { maneira precisa e } \\
\text { exata dos produtos } \\
\text { de degradação } \\
\text { desconhecidos } \\
\text { formados, } \\
\text { estressantes, }\end{array}$ & $\begin{array}{l}\text { Usar técnica de } \\
\text { cromatografia } \\
\text { líquida de alta } \\
\text { eficiência } \\
\text { (CLAE) para } \\
\text { doseamento do } \\
\text { princípio ativo e } \\
\text { seus produtos } \\
\text { de degradação. }\end{array}$ & $\begin{array}{l}\text { Foi verificado a formação } \\
\text { de produtos de degradação } \\
\text { diferentes dos já } \\
\text { encontrados nas literaturas } \\
\text { científicas do material, em } \\
\text { especial quando amostras } \\
\text { do material foram } \\
\text { submetidas às condições de } \\
\text { hidrólise alcalina e fotólise. }\end{array}$ & 2014 \\
\hline COSTA & $\begin{array}{l}\text { Acne vulgar: } \\
\text { estudo piloto de } \\
\text { avaliação do uso } \\
\text { oral de ácidos } \\
\text { graxos } \\
\text { essenciais por } \\
\text { meio de análises } \\
\text { clínica, digital e } \\
\text { histopa-tológica }\end{array}$ & $\begin{array}{l}\text { Verificar a resposta } \\
\text { clínicada racne } \\
\text { vulgar com o uso de } \\
\text { ácidos graxos } \\
\text { essenciais e quais os } \\
\text { melhores métodos } \\
\text { de avaliação do } \\
\text { tratamento. }\end{array}$ & $\begin{array}{ll}\text { Trinta e } & \text { um } \\
\text { voluntários, dos } \\
\text { quais r } & 16 \\
(51,6 \%) & \\
\text { receberam } & \\
\text { esquema oral } \\
\text { rico em ácidos } \\
\text { graxos } \\
\text { essenciais e } & 15 \\
\text { receberam pla- } \\
\text { cebo (48,4\%). } \\
\text { Foram } \\
\text { utilizadas } \\
\text { análises clínica, } \\
\text { de } \\
\text { avaliação, auto- } \\
\text { digital } \\
\text { histológica para } \\
\text { avaliação. }\end{array}$ & $\begin{array}{l}\text { Não houve diferença nas } \\
\text { notas subjetivas }(\mathrm{p}=0,419) \\
\text { e na análise digital } \\
\text { ( } \mathrm{p}=0,2187 \text { ) entre os gupos } \\
\text { placebo e produto; } \\
\text { ausência de correlação } \\
\text { estatística entre a análise } \\
\text { digital e a nota subjetiva } \\
\text { dos voluntários ( } \mathrm{p}=0,127 \text { ), } \\
\text { entre a nota subjetiva ea } \\
\text { resposta histopatológica } \\
\text { ( } \mathrm{p}=0,438 \text { ); houve, porém, } \\
\text { relação entre a análise } \\
\text { histopatológica e a digital } \\
\text { ( } \mathrm{p}=0,012)\end{array}$ & 2007 \\
\hline
\end{tabular}




\begin{tabular}{|c|c|c|c|c|c|}
\hline SAPER et al & $\begin{array}{lr}\text { Tratamento } & \text { da } \\
\text { infecção } & \text { por } \\
\text { Propionibacteri } \\
\text { um acnes } & \text { após } \\
\text { cirurgia } & \text { de } \\
\text { ombro } & \end{array}$ & $\begin{array}{l}\text { Criar base para uma } \\
\text { revisão de literatura } \\
\text { sobre o P. Acnes em } \\
\text { infecçãorapós } \\
\text { cirurgia de ombro }\end{array}$ & $\begin{array}{l}\text { Revisão única } \\
\text { ou em duas } \\
\text { etapas, r e } \\
\text { antibióticos } \\
\text { intravenosos }\end{array}$ & $\begin{array}{l}\text { A biópsia aberta antes da } \\
\text { implantação final (revisão } \\
\text { em duas etapas) pode ajudar } \\
\text { a detectar infecção } \\
\text { persistente por P. acnes. A } \\
\text { penicilina e as } \\
\text { cefalosporinas são eficazes } \\
\text { contra a infecção clínica de } \\
\text { P. acnes e o biofilme in } \\
\text { vitro. }\end{array}$ & 2015 \\
\hline BRENNER et al & $\begin{array}{l}\text { Opções } \\
\text { terapeuticas } \\
\text { para pacientes } \\
\text { com acne }\end{array}$ & $\begin{array}{l}\text { Esclarecer } \\
\text { médico generalista } \\
\text { as nuances da acne e } \\
\text { seu } \\
\text { tratamento,avaliand } \\
\text { o o custo e o } \\
\text { benefício r das } \\
\text { terapêuticas } \\
\text { disponíveis. }\end{array}$ & $\begin{array}{l}\text { Revisão de } \\
\text { literatura }\end{array}$ & $\begin{array}{l}\text { É preciso avaliar o custo e } \\
\text { obenefício das drogas e as } \\
\text { melhores indicações } \\
\text { confor-me o aspecto clínico } \\
\text { das lesões. }\end{array}$ & 2006 \\
\hline $\begin{array}{l}\text { ADDOR; } \\
\text { SCHALKA }\end{array}$ & $\begin{array}{l}\text { A acne da } \\
\text { mulher adulta }\end{array}$ & $\begin{array}{lr}\text { Analisar } & \text { as } \\
\text { características } & \\
\text { prevalentes } & \text { na } \\
\text { mulher adulta } & \text { com } \\
\text { acne } & \text { sem } \\
\text { hiperandrogenismo. }\end{array}$ & $\begin{array}{l}\text { Estudo } \\
\text { realizado com } \\
226 \text { mulheres } \\
\text { com queixa de } \\
\text { acne, sendo } \\
51,6 \% \text { não } \\
\text { apresentavam } \\
\text { alterações } \\
\text { homonais. } \\
\text { Foram } \\
\text { pesquisados } \\
\text { diversos tópicos } \\
\text { para melhor } \\
\text { compreende-lo }\end{array}$ & $\begin{array}{l}\text { A média das idades foi de } \\
33,9 \text { anos e o grau clínico } \\
\text { predominante foi o } \\
\text { inflamatório moderado } \\
\text { (grau II); a face foi a área } \\
\text { mais acometida. Os } \\
\text { retinoides tópicos foram as } \\
\text { drogas mais prescritas, e a } \\
\text { medicação sistêmica foi } \\
\text { indicada em } 53,4 \% \text { das } \\
\text { pacientes. }\end{array}$ & 2010 \\
\hline $\begin{array}{l}\text { PINTO; ROSA; } \\
\text { SILVA }\end{array}$ & $\begin{array}{l}\text { Uso de } \\
\text { hidroxíacidos } \\
\text { como } \\
\text { tratamento de } \\
\text { peeling químico } \\
\text { para acne }\end{array}$ & 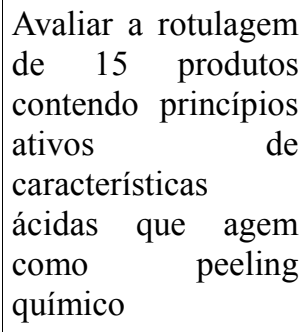 & $\begin{array}{l}\text { Pesquisa } \\
\text { bibliográfica e } \\
\text { documental, }\end{array}$ & $\begin{array}{l}\text { todos os cosméticos a maior } \\
\text { predominância de AHAs } \\
\text { presentes nas formulações e } \\
\text { o ácido glicólico }(53,3 \%) \\
\text { dos produtos }\end{array}$ & 2011 \\
\hline LEYDEN & $\begin{array}{l}\text { Combinações de } \\
\text { Terapias para o } \\
\text { tratamento de } \\
\text { acne vulgaris }\end{array}$ & $\begin{array}{l}\text { Avaliar tratamentos } \\
\text { disponíveis para a } \\
\text { acne, com base nos } \\
\text { seus efeitos sobre os } \\
\text { factores patogénicos } \\
\text { subjacentes à doença }\end{array}$ & $\begin{array}{l}\text { Revisão de } \\
\text { literatura }\end{array}$ & $\begin{array}{l}\text { O uso de terapias de } \\
\text { combinação desde o início } \\
\text { da terapia tem o potencial } \\
\text { para melhorar o tratamento, } \\
\text { produzindo resultados } \\
\text { maiores e mais rápidos e } \\
\text { simplificam a gestão para o } \\
\text { dermatologista, levando a } \\
\text { uma maior satisfação do } \\
\text { paciente e conformidade } \\
\text { com a terapia. }\end{array}$ & 2003 \\
\hline
\end{tabular}


Id on Line Revista Multidisciplinar e de Psicoloqia

Id on Line Multidisciplinary and Psycology Journal

\begin{tabular}{|c|c|c|c|c|c|}
\hline GUERRA et al & $\begin{array}{lr}\text { Utilização } & \text { de } \\
\text { agente } & \text { de } \\
\text { peeling químico } \\
\text { nos tratamentos } \\
\text { faciais }\end{array}$ & $\begin{array}{l}\text { Realizar um } \\
\text { levantamento } \\
\text { bibliográfico a } \\
\text { respeito da } \\
\text { utilização dos } \\
\text { principais agentes } \\
\text { de peelings } \\
\text { químicos nos } \\
\text { tratamentos faciais, } \\
\text { evidenciand o assim } \\
\text { sua eficácia }\end{array}$ & $\begin{array}{l}\text { Revisão } \\
\text { literatura }\end{array}$ & $\begin{array}{l}\text { Concluiu-se assim que os } \\
\text { peelings } \\
\text { apresentam químicos } \\
\text { satisfatórios em difersos } \\
\text { distúrbios de pele e as } \\
\text { soluções mais utilizadas são } \\
\text { os ácidos e os fenois }\end{array}$ & 2013 \\
\hline
\end{tabular}

Fonte: Elaborada pela autora

\section{A Pele humana}

A maior parte do corpo humano é revestido por algum tipo de tecido epitelial, sendo o principal deles, a pele (SOCIEDADE BRASILEIRA DE CIRURGIA DERMATOLÓGICA, 2009). A pele atinge $16 \%$ peso corporal e exerce várias funções, sendo um isolante térmico, controlador da corrente sanguínea, principal tecido do sentido do tato entre outros (GONÇALVES; RABEH; TERÇARIOL, 2015). Restabelecendo a superfície do corpo constituída por uma porção epitelial que tem origem ectodérmica, a epiderme, e também uma parte conjuntiva que tem origem mesodérmica, a derme. (JUNQUEIRA; CARNEIRO, 2008; GATHAS et al., 2011).

A pele humana, pode ser entendida como um órgão formado por um epitélio estratificado, pavimentoso queratinizado podendo haver alguma estruturas modificadoras quando necessários, como: melanócitos, células de Langerhans, queratinócitos, células sebáceas dentre outros (SOCIEDADE BRASILEIRA DE CIRURGIA DERMATOLÓGICA, 2009).

Este grande órgão pode ser utilizado pelo organism humano como uma barreira entre o organismo e o ambiente sendo constituída por três tipos de estruturas: camada córnea, camada espinhosa e um manto lipídico. Ela tem a função de proteger o corpo tanto da perda de substâncias importantes quanto contra a entrada de agentes prejudiciais (GATHAS et al., 2011). A pele é vulnerável e passível de desequilíbrios no controle de substâncias endógenas e nas agressões exógenas (MINISTÉRIO DA SAÚDE, 2014). 


\section{A acne}

Acne é um processo inflamatório que acomete seu aparecimento principalmente em adolescentes, sendo o maior motivo da ida deste grupo etário à dermatologistas (GIUSTI, 2015), mas que pode se estender pela vida adulta (ZAENGLEIN, 2008). No processo de formação da acne, os principais pilares da patogênese são apresentados como a formação do cômedo, a produção de sebo, a colonização bacteriana e o processo inflamatório (DIAS, 2014).

As glândulas pilossebáceas sofrem uma modificação decorrente da hipertrofia de sua estrutura causada pela a ação androgênica, criando condições para a formação do comedões (GUISTI, 2015). Além disso, ocorre a hiperproliferação do infundíbulo (canal excretor) da glândula, propiciando uma oclusão da região e impedindo a drenagem do sebo, formando uma rolha e favorecendo a comedogênese (COSTA et al, 2007).

Simultaneamente, a hiperestimulação androgênica possibilita a produção excessiva de sebo, ou seja, grande quantidade de secreção fica retida e propiciando a colonização principalmente pela bactéria Propionibacterium acnes (GUISTI, 2015). Este bacilo grampositivo é um comensal da pele humana, princialmente no rosto, peito e axilas, apresenta melhor desenvolvimento em anaerobiose. Entretanto, desencadeando a instalação de um processo inflamatório e infeccioso em toda a glândula (SAPER et al, 2015; BRENNER et al, 2006).

As características clínicas da acne norteiam a classificação como sendo acne não inflamatória, grau I, acne inflamatória, graus II, nesta fase as lesões pápulo-pustulosas são mais predominates que os comedões, III, pode-se observar nódulos e cistos, na IV ou conglobata é uma forma severa com múltiplos nódulos inflamatórios, formação de abscessos e fístulas, por fim a acne grau $\mathrm{V}$ ou fulminante é a forma mais grave e rara, sendo acompanhada de manifestações sistêmicas como febre, leucocitose e artralgia (BRENNER et al, 2006).

O diagnóstico da acne é excluisivamente clínico, podendo aparecer a acne nas costas, face e no tórax, e até mesmo a comedões devido a oxidação das gorduras e acréscimo da melanina, e assim surgindo em algumas pessoas a formação da pústula com até $1 \mathrm{~cm}$ de diâmentro (ADDOR; SCHALKA, 2010).

No que diz respeito aos cistos, nódulos e abscessos, estes possuem tamanhos variados e configura a fase avançada da acne, eles deixam cicatrizes que podem ser consequência das 
lesões inflamatórias, ou o resultado da manipulação das lesões pela destruição das células germinativas localizadas na região mediana do folículo (PIMENTEL, 2008).

Quanto à fisiopatologia pode-se seprarar em 4 fases principais, são elas Hiperplasia sebácea, Anomalia queratinoctária, colonização pelo micro-organismos e por último, há uma reação inflamatória na região afetada, estes passos estão descritos na tabela abaixo (Tabela 2).

Tabela 2 - As fases da fisiopatologia da ACNE

1. Hiperplasia sebácea

Na primeira fase, há aumento da produção de gordura e óleos na região, unido a este fato os hormônios andrôgenos passam a estar em contato com a $5 \alpha$-reductase tipo I são convertidos a dihidrotestosterona que criam áreas seborréicas.

2. Anomalias na diferenciação Nesta fase o folículo piloso condiciona a obliteração do e adesão queratinocitária folículo e formação de comedões. Ocorrem lesões elementares da acne provocada pela inflamação, alterando os padrões estruturais da glândula por meio de hormônios, apresentando hipertrofia das glândulas pilossebáceas criando condições para os comedões. As mesmas formam uma espécie de bloqueio de dreno causando hiperestimulação do aparecimento dos comedões.

\begin{tabular}{ll}
\hline Colonização bacteriana & Quando se rompe a estrutura do comedão ocorre a \\
& colonização de Propionibacterium. acnes e com o \\
& crescimento deste comensal ocorre em poucas semanas a \\
& inflamação. \\
\hline Reação Inflamatória & $\mathrm{Na}$ fase finalizatória há liberação de mediadores \\
& inflamatórios e com ruptura da parede da glândula sebácea
\end{tabular}

Fonte: Adaptada de Guisti (2015)

Segundo o Ministério da saúde (2008, p. 394) alguns processos podem acarretar na piora da acne, como: 
- Fricção e pressão sobre as lesões causam rotura folicular e aparecimento de pápulas e pústulas;

- Cosméticos como cremes faciais podem levar à formação de comedões e pápulas; exposição solar intensa e o uso de cremes antiactínicos podem provocar pápulas e pústulas, com ausência ou poucos comedões;

- Uso excessivo de sabonetes pode ter ação comedogênica, pelos ácidos graxos, como também pelo hexaclorofeno dos sabões medicamentosos

- Medicamentos tópicos em cremes e pomadas pelos veículos com lanolina ou vaselina ou pelo medicamento, principalmente corticóides, podem induzir a formação de comedões e pápulas;

- Óleos e graxas minerais diretamente ou impregnando os vestuários levam à oclusão dos óstios foliculares, com aparecimento de pontos negros e formação de pápulas e nódulos inflamatórios (elaioconiose);

- Medicamentos sistêmicos mais freqüentemente responsáveis por erupções acneiformes são: corticosteróides, esteróides anabolizantes, vitaminas B1,B6 B12 e D2, anticonvulsivantes, carbonato de lítio, isoniazida, quinidina, tiouracil, tiouréia, ciclosporina $\mathrm{A}$, iodetos $\mathrm{e}$ brometos (MINISTÉRIO DA SAÚDE, 2008, p. 394).

O diagnóstico usado pelos dermatologistas e demais profissionais da área de estética para a acne é o dignótico clínico da análise das lesões, o aparecimento de comedões é positivo para a diagnose correta (ARAÚJO, DELGADO; MARÇAL, 2011). Segundo Brenner e seus colaboradores (2006 apud GUISTI, 2015, p. 19) os comedões se apresentam fechados, com aspecto esbranquiçado, geralmente medindo de $1 \mathrm{a} 2 \mathrm{~mm}$, ou aberto, de cor enegrecida devido à oxidação das gorduras e aumento da deposição de melanina, podendo evoluir com a formação de pústulas de até $1 \mathrm{~cm}$ de diâmetro.

\section{Tratamento}

O tratamento da acne compreende em técnicasde caráter tópico, sistêmico ou cirúrgico, isso vai depender de fatores tais como o grau de acometimento da pele, da tolerância do paciente bem como o poder aquisitivo, visto que existem modalidades de tratamento que custam caro (MANFRINATO, 2009).

A utilização do tratamento tópico é importante em indivíduos com acne podendo ser usado especificamente nas formas leves a moderadas, através de produtos prescritos como os antibióticos em associação a outros agentes como peróxido de benzoíla, nicotinamida e ácidos retinóico, azelaico e salicílico (LEYDEN, 2003; DIAS, 2014).

O tratamento sistêmico é considerado quando a acne se encontra no processo 
inflamatório e de difícil controle, podendo utilizar os antibióticos, antiandrógenoseretinóides sistêmicos, além disso, o tratamento pode ser hormonal no caso de mulheres com excesso de hormônios androgênicos ou hipersensibilidade periférica a eles, podendo ser utilizados os bloqueadores de receptores de androgênios, antiandrogênicos e inibidores da produção de androgênios adrenais ou ovarianos (BRENNER et al, 2006).

A atuação das técnicas estéticas permite o tratamento da acne de formas diversas dentre elas encontram-se a limpeza de pele que possibilita remover comedões para impedir a oclusão dos folículos pilossebáceos; a crioterapia utilizando gás carbônico $\left(\mathrm{CO}_{2}\right)$ e o nitrogênio líquido em lesões localizadas e severas que não respondem ao tratamento tópico e/ou sistêmico; a laserterapia e fototerapia, recomendada pelas propriedades terapêuticas antiinflamatórias, bactericida, bem como a capacidade de reorganizar o colágeno da pele; a geoterapia que promove a desintoxicação da pele e pelas propriedades terapêuticas anti-inflamatória e bactericida da argila; a microdermoabrasão, recomendada para uniformização da pele; e o peeling, usado para reduzir as manchas e cicatrizes mais superficiais da acne (SPETHMANN, 2007; PIMENTEL, 2008).

Produtos antimicrobianos também podem ser usados para controlar a acne, uma vez que, esta doença é motivada pela inflamação mediada pela $P$. acnes, são elas a tetraciclina e seus derivados ou a minociclina ou ainda em casos mais avançados as sulfas também podem ser usadas (PIMENTEL, 2008).

\section{Peeling}

O pelling pode ser utilizados nas práticas clínicas, para reduzir as manchas e cicatrizes mais superficiais da acne (ARAÚJO, DELGADO; MARÇAL, 2011), uma vez que, esta técnica vai promover uma renovação celular a partir da camada basal e provoca a síntese de colágeno e a reparação tecidual, melhorando assim o aspecto cutâneo. Indicado por profissionais da área da medicina e da estética pelo seu resultado satisfatório em uma melhor aparência na pele. (PIMENTEL, 2008 apud PINTO; ROSA; SILVA, 2011)

A técnica consiste na utilização de diversos ácidos para auxiliar na descamação das células da pele danificadas por algum agente causal biótico ou não, fazendo com que a estrutura 
de fibroblastos se regenere melhor a partir do epitélio estratificado mais liso, evitando sujidades sobre a região aplicada (ARAÚJO, DELGADO; MARÇAL, 2011).

Através do nível de profundidade da necrose do tecido os peelings são classificados em quatro grupos: o muito superficial que irão afinar ou remover o estrato córneo sem criar lesão abaixo do estrato granuloso, o superficial que promove uma necrose de parte ou de toda epiderme em qualquer parte do estrato granuloso até a camada de células basais, o médio que produz necrose da epiderme e de parte ou toda a derme papilar, e o profundo que produz necrose da epiderme e da derme papilar que se estende até a derme reticular (CUNHA, 2009).

\section{Peeling químico}

O peeling químico possibilita alteração na pele através do mecanismo que vai estimular o crescimento epidérmico decorrente da remoção do estrato córneo, que vai destruir algumas lesões da pele e logo após substituindo por um tecido normal, e a indução de uma reação inflamatória mais vasta que a necrose produzida pelo agente do esfoliante (KEDE, SABATOVICH,2004).

O procedimento do peeling químico tem objetivo de obter uma esfoliação com agentes apropriados, sendo aplicados diversos ácidos, mas alguns desses ácidos são mais utilizados como: retinóico, vitamina $\mathrm{C}$, ácido lático, fenol e o ácido salicílico (LACRIMANTI, 2008). No entanto, o ácido salicílico possui a ação superficial, sendo considerado seguro para diversos tipos de pele torna-se o agente para peeling, ideal para pessoas com acne (JACOBS; ROENIGK, 2010).

O tratamento estético realizado através do peeling químico visa à redução de cicatrizes deprimidas e irregulares decorrentes da acne (MANFRINATO, 2009). Entretanto a utilização do peeling químico deve ser contraindicada nos casos de fotoproteção inadequada, gravidez, estresse ou escoriações neuróticas, utilização por menos de seis meses a isotretinoína oral, cicatrização deficiente ou formação de queloides e história de hiperpigmentação pósinflamatória permanente(GUERRA et al., 2013).

O pelling já é utilizadoem diversos tratamentos de acne, grande parte dos dermatologistas usam a técnica como forma direta de limpeza, retirando as impurezas presentes 
nos comedões e retirar a oleosidade da pele, principalmente em adolescentes que apresentam maiores níveis hormonias androgênicos, o que leva ao maior acúmulo de glândulas sebáceas com seborreia (GUERRA et al., 2013).

No caso dos adolescentes outro fato é a maior elasticidade da pele, o que favorece o não aparecimento de rugas, neste caso é indicado o tipo de peeling químico I, uma vez que, a estrutura de fibroblastos está rígida favorescendo o desenvolvimento de novas células mais uniformes e estruturada (BIOMODULAÇÃO CORPORAL, 2015).

\section{Considerações Finais}

As diversas patologias conhecidas como acne, são formadas por sua maior parte questões hormonais, sendo mais recorrente em adolescentes pela mudanças hormonais já conhecidas nessas fases. Por suas características serem de fácil dignóstico pelo esteticista ou dermatologista, uma vez que apresenta lesões visíveis a olho nu, outra parte importante é seu tratamento, esta doença hoje apresenta vários modos de ser tratada, entretanto deve-se conhecer melhor a vida do paciente para identificar melhor seu dia a dia pra indicar o melhor.

Sendo assim, o peeling pode ser utilizada como uma técnica de esfoliação da pele no intuíto de remoção das estruturas que evitam a saída do compostos presentes nas glândulas sebáceas, evitando acúmulo, a infestação de patógeno e consequentemente inflamação da pele atingida.

Pode-se concluir que os peelings, incluindo os químicos, em diversos trabalhos apresentam resultados bons para diversos distúrbios de pele destacando a acne, podendo ser solução de diversos materiais que agem nas células criando um ambiente de esfoliação, entretanto as metodologias utilizadas foram pouco específicas o que dificulta sua reprodutibilidade.

\section{Referências}

ADDOR F. A. S.; SCHALKA, S. Acne in adult women. An Bras Dermatol, São Paulo, v. 85 
n. 6, pp. 789-95, 2010.

ARAÚJO, A. P. S.; DELGADO, D. C.; MARÇAL, R. Acne tipologias e formas de tratamento. Revista Médica da Santa Casa de Maceió, Maceió, v.1, n.1, p. 26-29, jan. 2011. Disponível em: http://www.cesumar.br/prppge/pesquisa/epcc2011/anais/ana_paula_serra_araujo\%20(3).pdf. Acesso em: 08 mai. 2017.

BIOMODULAÇÃO CORPORAL. Peeling Químico. 2015. Disponível em: < http://biomodulacaocorporal.com.br/peeling_quimico.htm >. Acesso em: 09 mai. 2017.

BRENNER, F.M; ROSAS, F.M.B.; GADENS, G.A.; SULZBACH, M.L.; CARVALHO, V.C.; TAMASHIRO, V. Acne: um tratamento para cada paciente. Rev. Ciênc. Méd., Campinas,v.15, n.3, p.257-266, maio/jun., 2006.

BORGES, F. S. Modalidades Terapêuticas nas Disfunções Estéticas. Phorte. São Paulo:305-23. 2006.

BRASIL. Ministério da Saúde. Secretaria de Vigilância em Saúde. Guia de vigilância em saúde. Brasília, 2014.

Ministério da Saúde. Fundação Oswaldo Cruz. Um olhar sobre o jovem no Brasil. Brasília, 2008b.

COSTA, A; MICHALANY, N. S.; ALCHORNE, M.M.A.; LIMA, H.C. Acne vulgar: estudo piloto de avaliação do uso oral de ácidos graxos essenciais por meio de analises clinica, digital e histopatológica.AnBrasDermatol, Campinas, v.82, n.2, p.129-34, 2007.

CUNHA, M.N. Experiência com peeling de ácido Salicílico a 30\% no tratamento de acne. Revista Oficial da Sociedade Brasileira de Medicina Estética. Junho. 2009.

DIAS, Fernando Lino. Desenvolvimento e validação de método indicador de estabilidade de formulações farmacêuticas de uso tópico contendo peróxido de benzoíla. 2014. Dissertação (Mestrado em Produção e Controle Farmacêuticos) - Faculdade de Ciências Farmacêuticas, Universidade de São Paulo, São Paulo, 2014. doi:10.11606/D.9.2014.tde24032014-112539. Acesso em: 2017-05-13.

GATHAS, A. Z.; DJALETA, D.G.; NOVIELlO, D.S.; THOMAZ, M.C.A.; ARÇARI, D.P. Atendimento do Enfermeiro ao Paciente Queimado Rev Eletrônica Unisepe, Saúde em Foco. 2011.

GIUSTI, M. M. C. G. Abordagem Homeopática na acne. 2015. Especialização (Monografia em Homeopatia) - CENTRO ALPHA DE ENSINO, ASSOCIAÇÃO PAULISTA DE HOMEOPATIA - São Paulo, 46 p., 2015.

GONÇALVES, M. B. B. Impacto do ensino a distância no conhecimento dos docentes de enfermagem para avaliação de feridas crônicas. 2014. Dissertação (Mestrado em Enfermagem Fundamental) - Escola de Enfermagem de Ribeirão Preto, Universidade de São 
Paulo, Ribeirão Preto, 2014. doi:10.11606/D.22.2014.tde-20052014-202245. Acesso em: 09 mai. 2017.

GUERRA， F.M.R.M; KRINSK， G. G.; CAMPIOTTO, L.G.; GUIMARÃES， K.M.F. Aplicabilidade dos peelingsquímicosemtratamentos faciais - estudo de revisão.Braz. J. Surg. Clin. Res, v.4,n.3,p.33-36, Set - Nov, 2013.

KEDE, M.P. V; SABATOVICH, O. Dermatologia Estética. Atheneu. São Paulo: 415-49. 2004.

KLUBER, T. E.; BURAK, D. Sobre a Pesquisa Qualitativa na Modelagem Matemática em Educação Matemática. Bolema, Rio Claro, v. 26, n. 43, p. 883-905, Aug. 2012. Disponível em: $<$ http://www.scielo.br/scielo.php?script=sci_arttext\&pid=S0103-

636X2012000300007\&lng=en\&nrm=iso $>$. Ácesso em : 09 Mai. 2017

JACOBS, M.A; ROENIGK R. Superficial chemical peels.In: Draelos ZD, editor. Cosmetic Dermatology: Products and Procedures. Ed. Singapore: Wiley-Blackwell; 2010. p.379.

LACRIMANTI,L,M. Curso didático de estética - volume 2.Yendis. São Paulo:51-2. 2008.

JUNQUEIRA, L.C.U.; CARNEIRO, J. Histologia Básica. 11ª Ed. Rio de Janeiro: Guanabara Koogan, 2008. 524p.

LEYDEN, J.J. A review of the use of combination therapiesfor the treatment of acnes vulgaris.J Am AcadDermatol. 2003; 49:S200-10.

LIMA, L.A.F. Acne na mulher adulta e tratamento. Revista Médica da Santa Casa de Maceió, Maceió, v.1, n.1, p. 26-29, jan. 2006.

MANFRINATO, G.L. Acupuntura estética no tratamento da acne (estudo de caso).2009. 58f. Monografia (Especialização em Acupuntura) - Instituto Brasileiro de Therapiasm e Ensino, Maringá, 2009.

PIMENTEL, A. S. Peeling, máscara e acne: seus tipos e passo a passo do tratamento estético. São Paulo: LMP; 2008. 336p.

PINTO, B.; ROSA, S.; SILVA, D. Peelings químicos faciais utilizados em protocolos estéticos. 2011. Disponível em: http://siaibib01.univali.br/pdf/bruna\%20pinto,\%20samanta\%20da\%20rosa.pdf Acesso em: 03 de jan. 2017.

RIVITTI,E. A.; SAMPAIO, S. A. P. Dermatología.2a.ed.SãoPaulo: Artes Médicas; 2000.

ROTTA, O.; et al Guia de dermatologia: clínica, cirúrgica e cosmiátrica. $1^{\mathrm{a}}$ ed. Barueri, SP: Manole, 2008. P. 689-696. 
Id on Line Revista Multidisciplinar e de Psicoloqia

Id on Line Multidisciplinary and Psycology Journal

SAPER, D.; CAPIRO, N.; MA, R.; LI, X. Management of Propionibacterium acnes infection after shoulder surgery. Curr Rev Musculoskelet Med, Boston, v. 8, pp.67-74, 2015.

SOCIEDADE BRASILEIRA DE CIRURGIA DERMATOLÓGICA. Fisiologia. 2010. Disponível em: < https://www.sbcd.org.br/pagina/1615 >. Acesso em: 09 mai. 2017.

SPETHMANN, C. N. Medicina alternativa de A a Z. 7.ed. Uberlândia: Editora natureza, 2007. 392p.

SUDO, E.; FILHO, L. Principio Fisiológicos da ACNE e a utilização de diferentes tipos de ácidos como forma de tratamento. 2014. Disponível em: < http://portalbiocursos.com.br/ohs/data/docs/18/88

PrincYpios_FisiolYgicos_da_ACNE_e_a_utilizaYYo_de_diferentes_tipos_de_Ycidos_como_ forma_de_Tratamento.pdf. $>\bar{A}$ Acesso em: 03 de jan. 2016 .

ZAENGLEIN, A. L.; GRABER, E. M.; THIBOUTOT, D. M. Acne vulgaris and acneiform eruptions. In: Wolff K, GoldsmithLA, Katz SI, Gilchrest BA, Paller AS, Leffell DJ, editors.Fitzpatrick's, Dermatology in general medicine.;p. 690-692, 2008.

Como citar este artigo (Formato ABNT):

ARAÚJO, Larissa D.; BRITO, Josy Q.A. Uso do Peeling Químico no Tratamento da Acne Grau II: Revisão Sistemática. Id on Line Revista Multidisciplinar e de Psicologia, Abril de 2017, vol.11, n.35, p. 100-115. ISSN: 1981-1179.

Recebido: 15.05 .2017

Aceito: .17.05.2017 